\title{
A QM/MM study of the Fosfomycin resistance
}

\section{mechanism involving FosB enzyme}

Anderson H. Lima*, José Rogério A. Silva, Cláudio Nahum Alves, Jerônimo Lameira

Universidade Federal do Pará, Laboratório de Planejamento e Desenvolvimento de Fármacos, Instituto de Ciências Exatas e Naturais, Rua Augusto Corrêa, 01. Postal code 66075-110, Belém, Pará, Brasil.

*Corresponding author: anderson@ufpa.br

\section{SUPPORT INFORMATION}

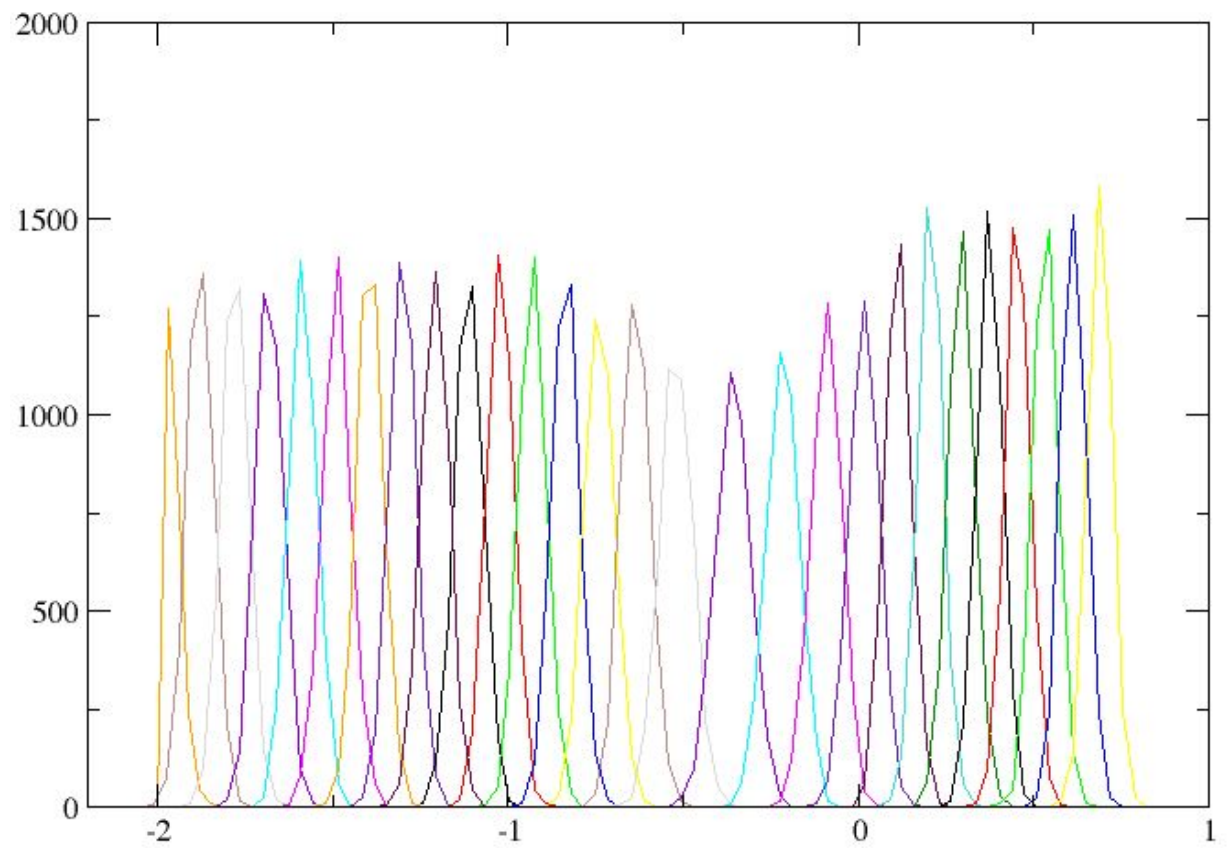

Figure S1. Distributions of reaction coordinates in different windows sampled during the US simulations. 


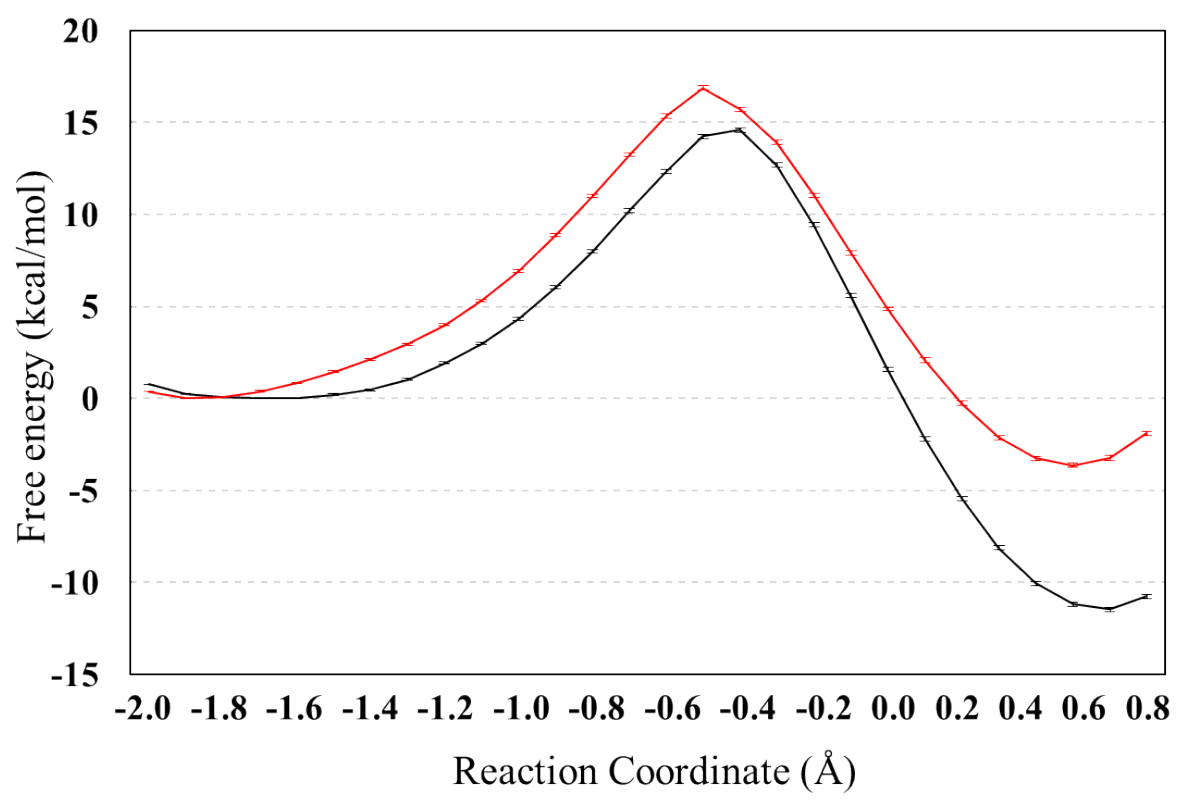

Figure S2. Potential of mean force for opening Fosfomycin oxirane ring at $\mathrm{C} 1$ atom (black line) and $\mathrm{C} 2$ atom (red line), at PM6/MM level. The error bars were calculated by Weighted Histogram Analysis Method (WHAM) with num_MC_trials=20 and randSeed=2084 for Monte Carlo bootstrap error analysis (Grossfield, Alan, "WHAM: the weighted histogram analysis method", version 2.0.10), http://membrane.urmc.rochester.edu/wordpress/?page_id=126.

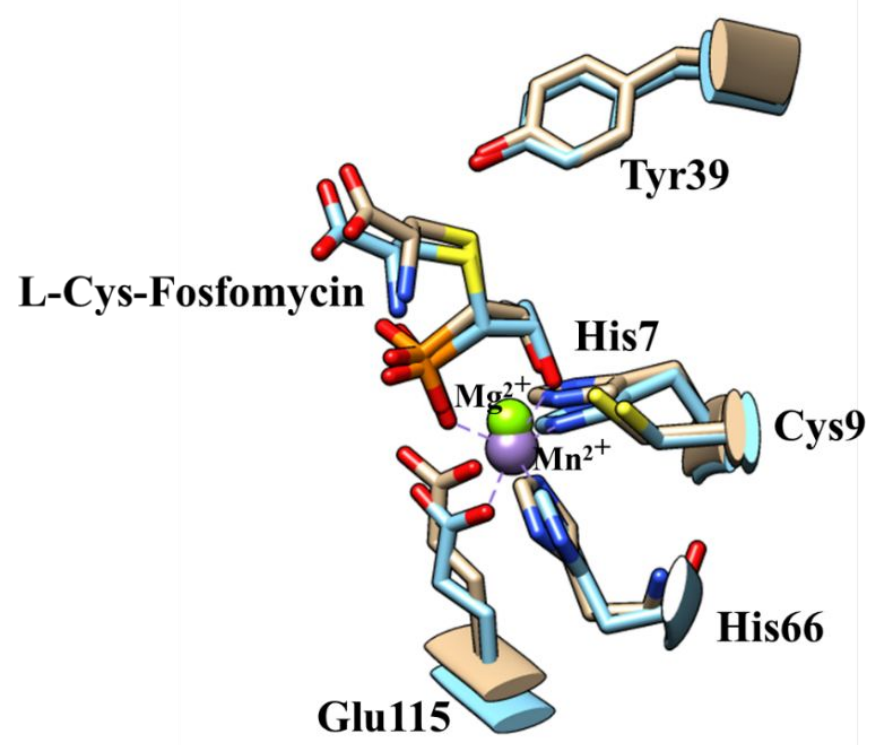

Figure S3. The representative structure of the product state from QM/MM US simulations has C atoms colored in light brown, while PDB 4JH7 (Crystal Structure of FosB with Manganese and L-CysteineFosfomycin Product) has C atoms colored in sky blue. The superimposition of the structures presented a root-mean-square deviation of $0.93 \AA$. 


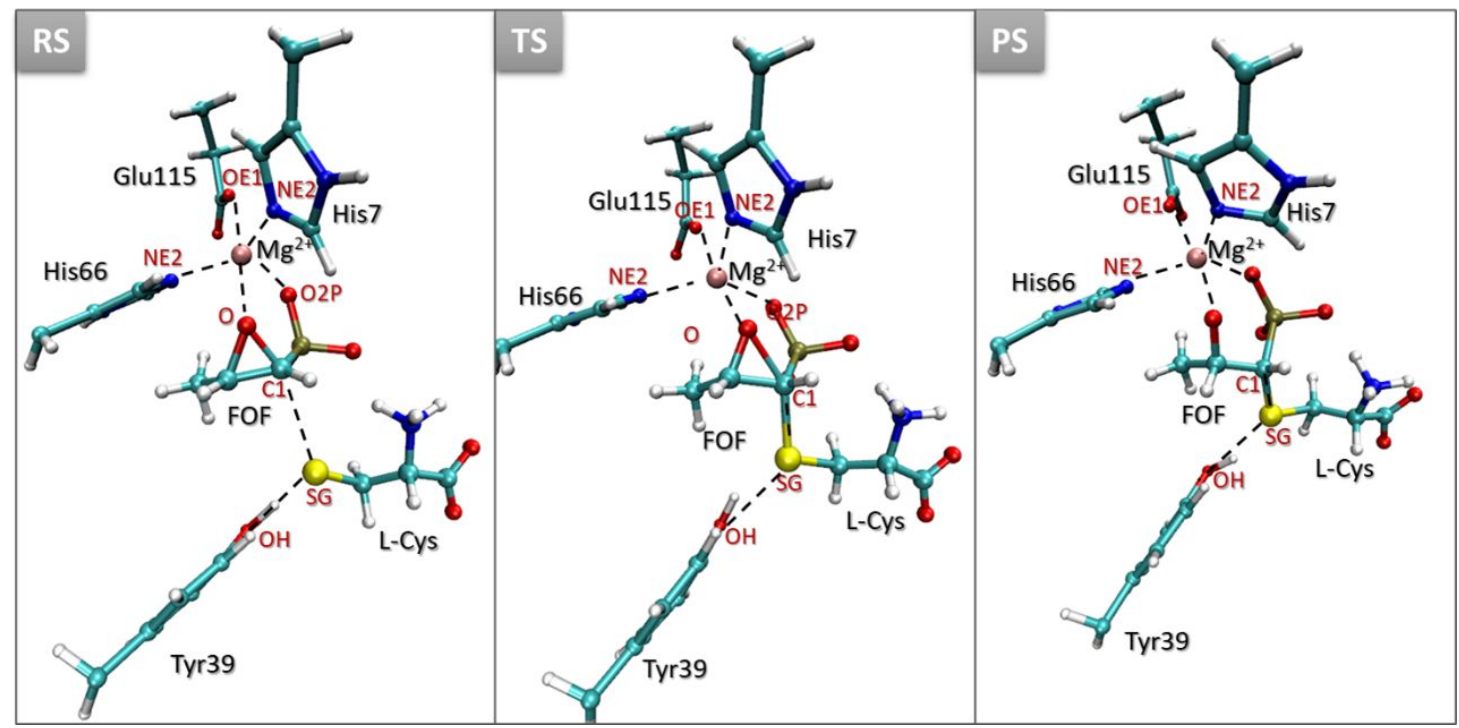

Figure S4. Main interactions in the mechanis of opening Fosfomycin oxirane ring at $\mathrm{C} 1$ atom.

Table S1. Averaged distances obtained along the reaction mechanism of Fosfomycin inactivation by FosB enzyme.

\begin{tabular}{|c|c|c|c|}
\hline \multicolumn{4}{|c|}{ Distances (in $\AA$ ) } \\
\hline & Reactant & Transition State & Product \\
\hline FOF $1-S_{\text {LCys }}$ & $3.18( \pm 0.05)$ & $2.20( \pm 0.04)$ & $1.79( \pm 0.03)$ \\
\hline FOF C1-O & $1.47( \pm 0.03)$ & $1.82( \pm 0.05)$ & $2.39( \pm 0.04)$ \\
\hline${ }_{\text {Tyr39}} \mathrm{OH}-\mathrm{SG}_{\mathrm{LCys}}$ & $2.87( \pm 0.08)$ & $2.99( \pm 0.15)$ & $3.20( \pm 0.19)$ \\
\hline FOF O- $\mathrm{Mg}^{2+}$ & $2.23( \pm 0.14)$ & $1.99( \pm 0.06)$ & $1.99( \pm 0.07)$ \\
\hline FOF $\mathrm{O} 2 \mathrm{P}-\mathrm{Mg}^{2+}$ & $2.02( \pm 0.06)$ & $2.08( \pm 0.07)$ & $2.09( \pm 0.08)$ \\
\hline His7 NE2-Mg ${ }^{2+}$ & $2.05( \pm 0.05)$ & $2.06( \pm 0.06)$ & $2.08( \pm 0.07)$ \\
\hline His66 NE2-Mg $^{2+}$ & $2.03( \pm 0.06)$ & $2.07( \pm 0.06)$ & $2.07( \pm 0.06)$ \\
\hline Glu115OE2-Mg ${ }^{2+}$ & $1.94( \pm 0.05)$ & $1.98( \pm 0.06)$ & $2.01( \pm 0.06)$ \\
\hline
\end{tabular}


OFF file format for Fosfomycin in Amber FCN.lib

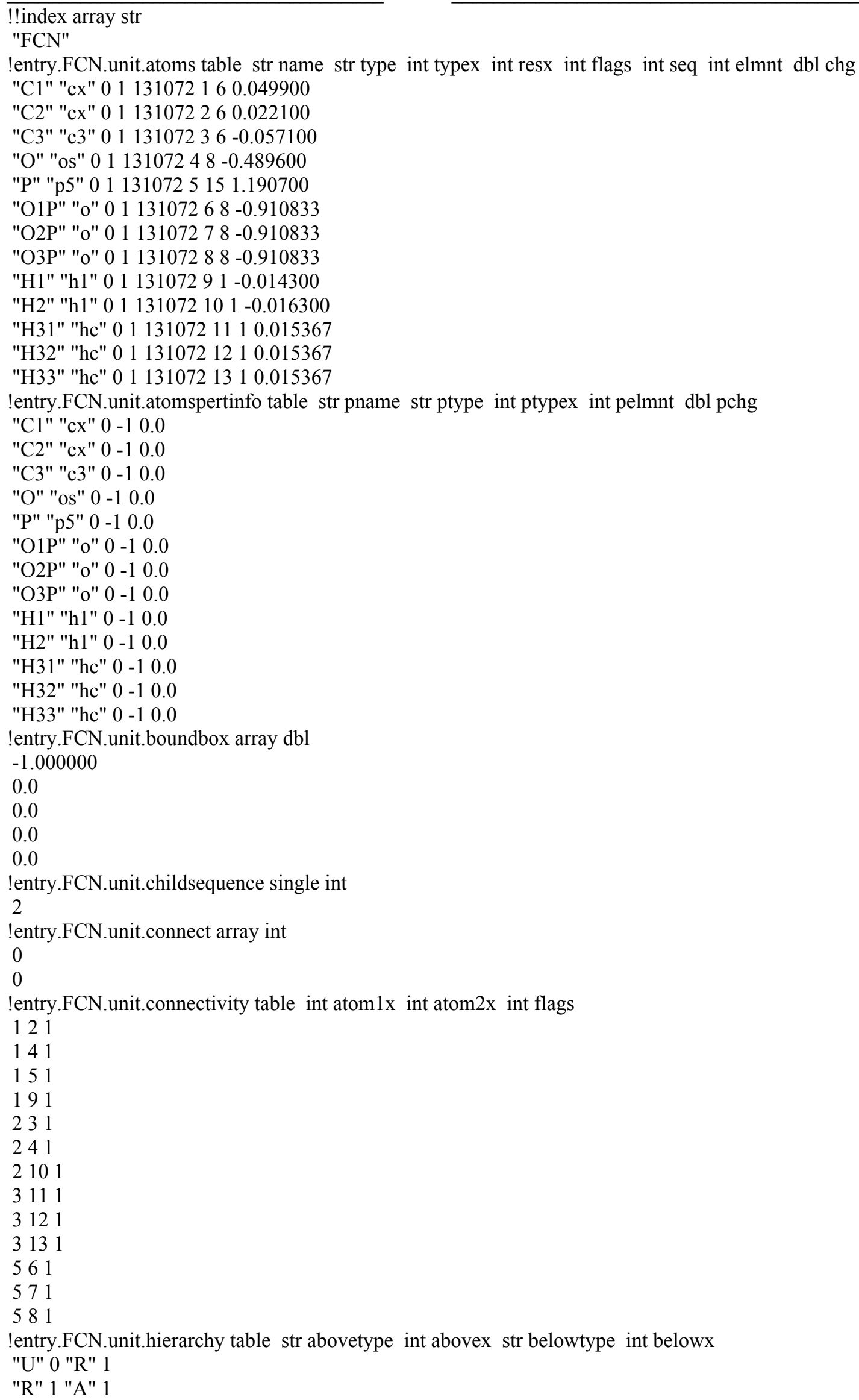




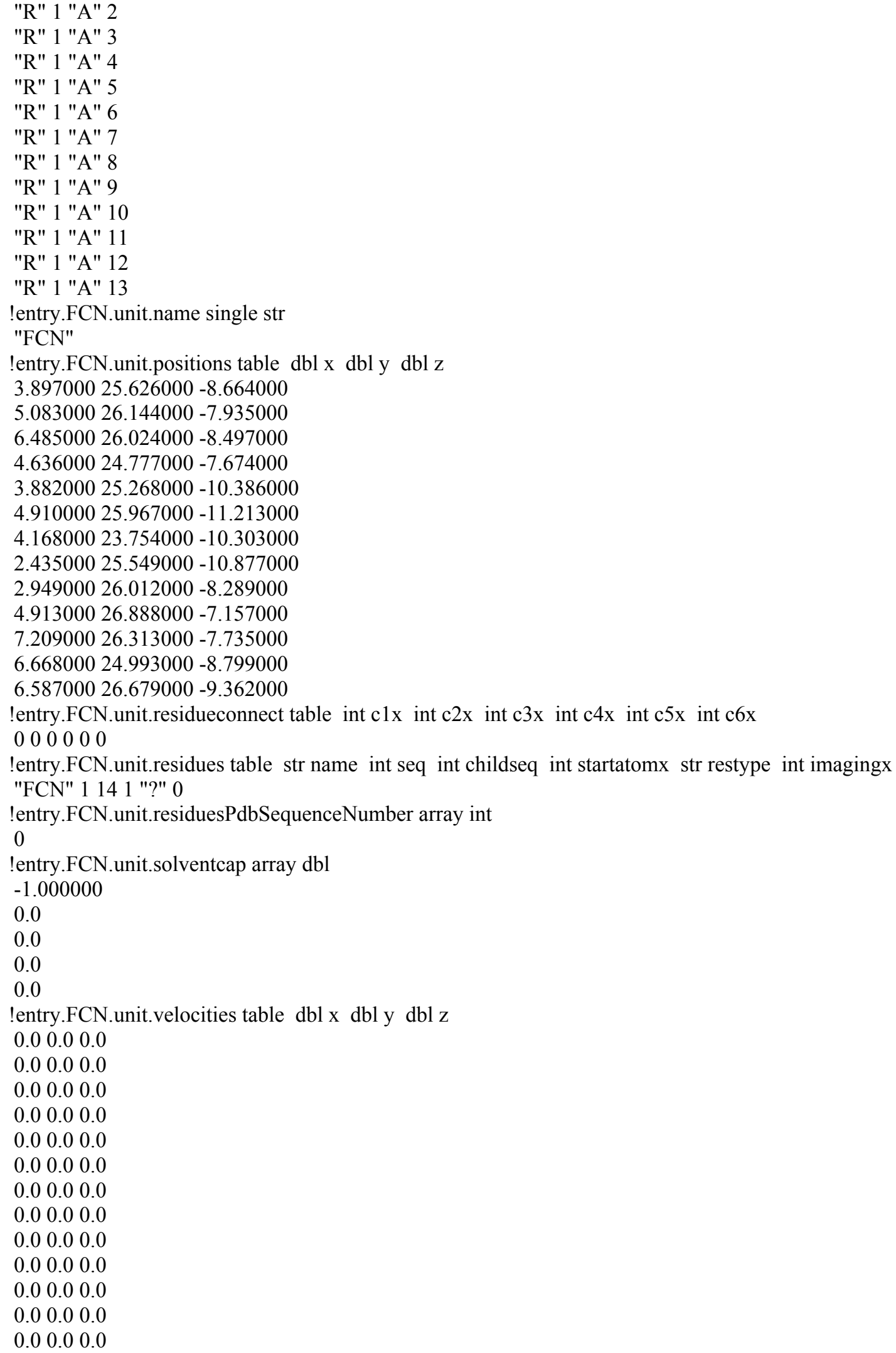


OFF file format for L-Cys in Amber

LCY.lib

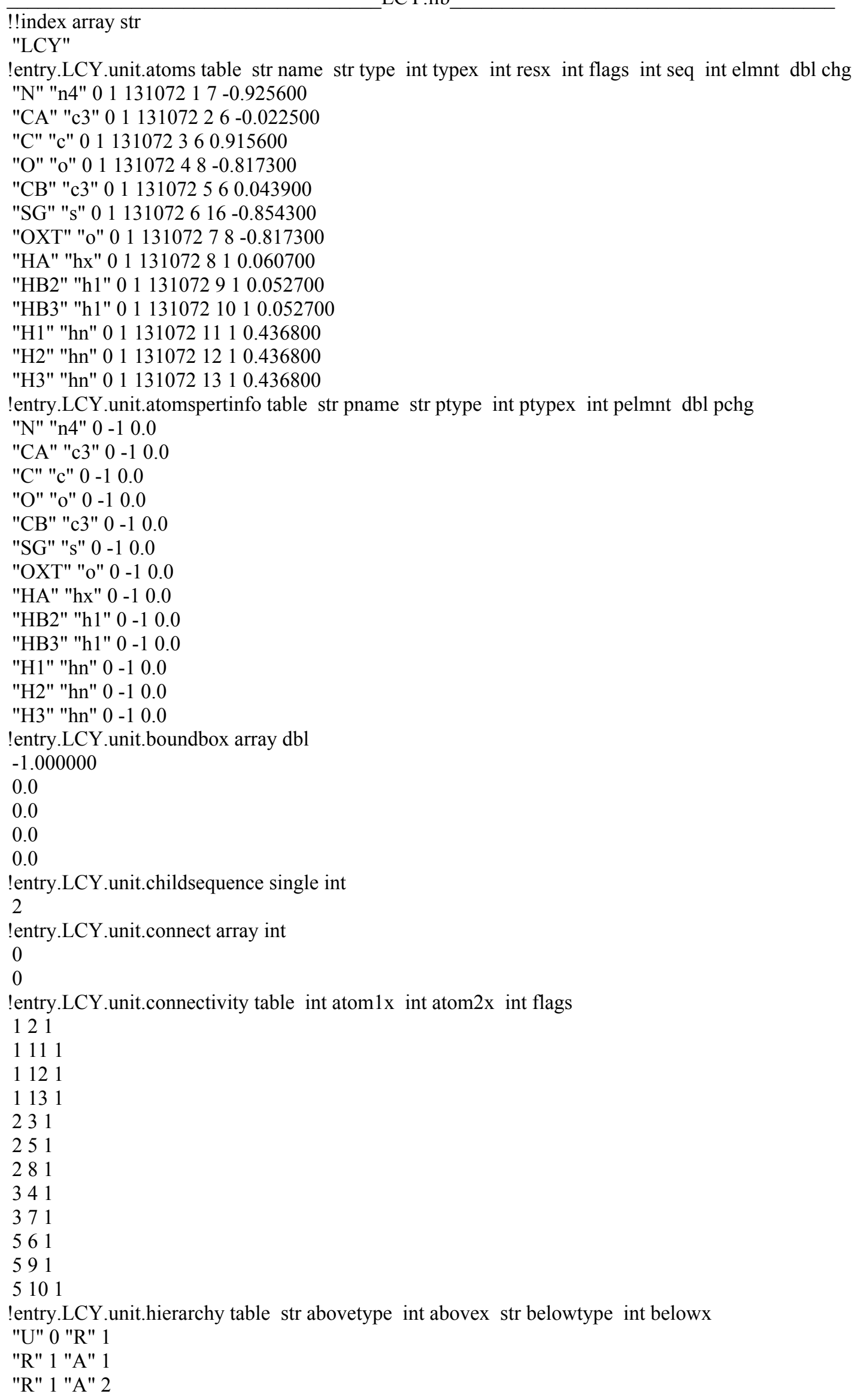




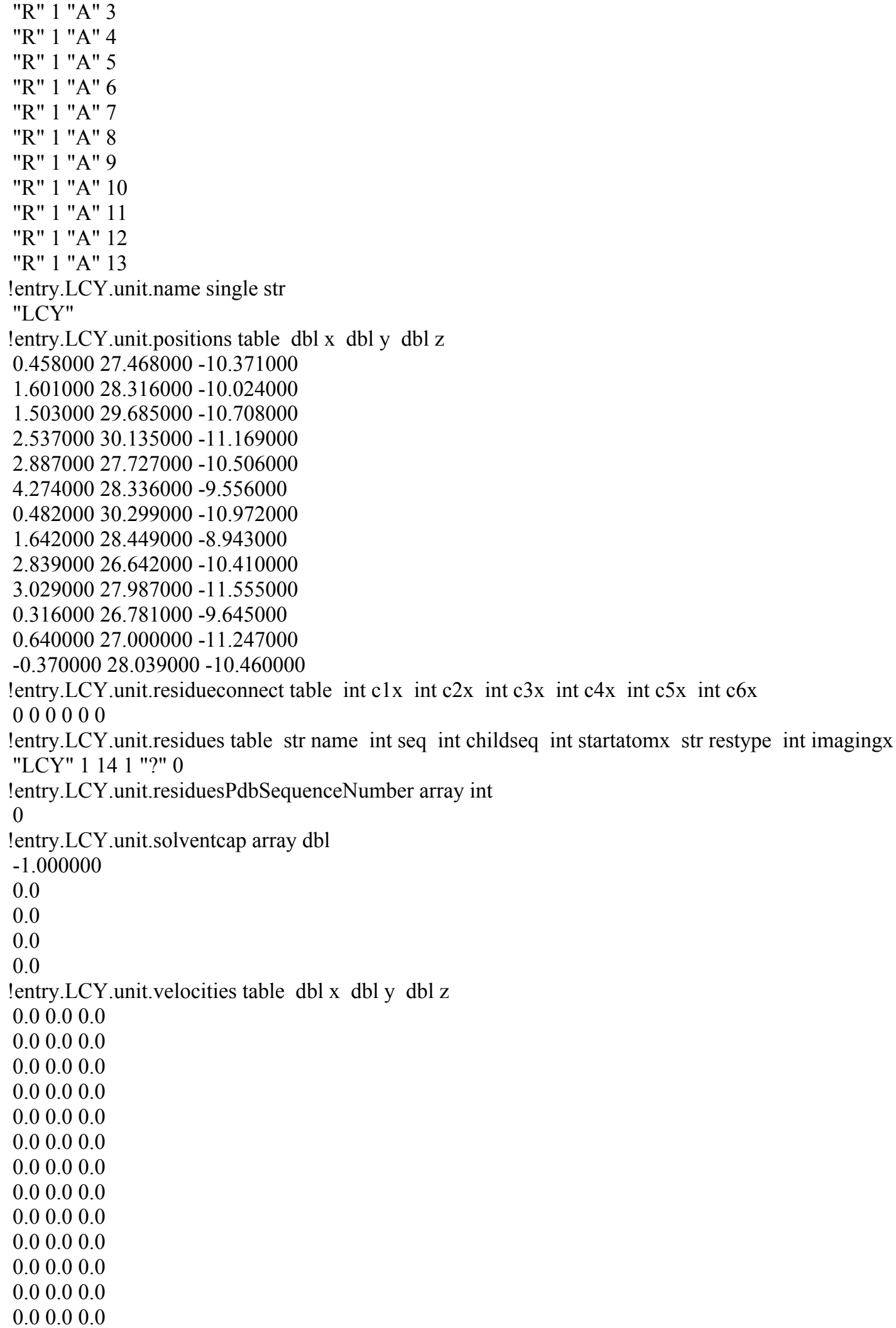

